\title{
X11 $\alpha$ MODULATES SECRETORY AND ENDOCYTIC TRAFFICKING AND METABOLISM OF AMYLOID PRECURSOR PROTEIN: MUTATIONAL ANALYSIS OF THE YENPTY SEQUENCE
}

\author{
G. D. KING, a R. G. PEREZ, ${ }^{b}$ M. L. STEINHILB, ${ }^{c, d}$ \\ J. R. GAUT ${ }^{\text {,dd }}$ AND R. S. TURNER ${ }^{a, c, e, f *}$ \\ ${ }^{a}$ Neuroscience Program, University of Michigan, Ann Arbor, MI 48109, \\ USA \\ ${ }^{b}$ Department of Neurology, University of Pittsburgh, Pittsburgh, PA \\ 15260, USA \\ 'Institute of Gerontology, University of Michigan Medical Center, Ann \\ Arbor, MI 48109, USA \\ ${ }^{d}$ Department of Biological Chemistry, University of Michigan Medical \\ Center, Ann Arbor, MI 48109, USA \\ ${ }^{e}$ Department of Neurology, University of Michigan Medical Center, Ann \\ Arbor, MI 48109, USA \\ ${ }^{f}$ Veterans Affairs Medical Center Geriatric Research, Education, and \\ Clinical Center, Ann Arbor, MI 48015, USA
}

\begin{abstract}
The neuronal adaptor $\mathrm{X} 11 \alpha$ interacts with the conserved -GYENPTY - sequence in the C-terminus of amyloid precursor protein (APP) or its Swedish mutation (APPswe) to inhibit $A \beta 40$ and $A \beta 42$ secretion. We hypothesized that the -YENP- motif essential for APP endocytosis is also essential for X11 $\alpha$-mediated effects on APP trafficking and metabolism, and that $\mathrm{X} 11 \alpha$ modulates APP metabolism in both secretory and endocytic pathways. $X 11 \alpha$ failed to interact with the endocytic-defective APPswe mutants Y738A, N740A, or P741A, and thus did not modulate their trafficking or metabolism. However, endocytic-competent APPswe Y743A had unique trafficking and metabolism including a prolonged half-life and increased secretion of catabolites compared with APPswe. In contrast to endocytic-defective mutants, $\mathrm{X} 11 \alpha$ interacted with APPswe Y743A as well as with APPswe. Thus, similar to APPswe, coexpression of X11 $\alpha$ with APPswe Y743A retarded its maturation, prolonged its half-life, and inhibited APPs, A 340 , and $A \beta 42$ secretion. Collectively, these data suggest that by direct interaction with the APPswe
\end{abstract}

${ }^{*}$ Correspondence to: R. S. Turner, Veterans Affairs Medical Center Geriatric Research, Education, and Clinical Center, 2215 Fuller Road, Ann Arbor, MI 48105, USA. Tel: +1-734-761-7686; fax: +1-734-7617489.

E-mail address: raymondt@umich.edu (R. S. Turner).

Abbreviations: AD, Alzheimer's disease; APP, amyloid precursor protein; APPs, secreted N-terminal ectodomain of APP; APPs $\alpha$, secreted $\alpha$-secretase cleavage product of APP; APPs $\beta$, secreted $\beta$-secretase cleavage product of APP; APPs $\alpha$ swe, secreted $\alpha$-secretase cleavage product of APPswe; APPs $\beta$ swe, secreted $\beta$-secretase cleavage product of APPswe; APPswe, amyloid precursor protein Swedish mutation (K651N/M652L); BM, binding medium; DMEM, Dulbecco Modified Eagle medium; ELISA, enzyme-linked immunosorbent assay; FAD, familial Alzheimer's disease; HEK, human embryonic kidney; SDS-PAGE, sodium dodecyl sulfate-polyacrylamide gel electrophoresis; PDZ, repeated sequences in Post-synaptic density-95 (PSD-95); D. melanogaster septate junction protein Disks-large, and epithelial tight junction protein Zona occludens-1; PTB, phosphotyrosine binding; Y738A, N740A, P741A, and Y743A all refer to APPsweY738A, APPswe N740A, APPswe P741A, and APPswe Y743A, respectively.
-YENP - motif in the cytoplasmic tail, X11 $\alpha$ modulated its trafficking and processing in both secretory and endocytic compartments, and may reduce secretion of $A \beta$ generated in either pathway. (๑) 2003 IBRO. Published by Elsevier Science Ltd. All rights reserved.

Key words: amyloid precursor protein, XIl $\alpha$, mint-1, A $\beta$, Alzheimer, processing.

Alzheimer's disease $(A D)$ is a progressive neurodegenerative disorder that is pathologically defined by the density of neurofibrillary tangles and amyloid plaques in brain. The major components of amyloid plaque in $A D$ brain are $A \beta$ peptides, including $A \beta 40$ and $A \beta 42$, that are derived by $\beta$ and $\gamma$-secretase cleavage of the type I transmembrane glycoprotein amyloid precursor protein (APP). In the $\beta-/ \gamma-$ secretase pathway of APP catabolism, the secreted Nterminal ectodomain of APP is known as APPs $\beta$. Alternatively, APP may be metabolized by $\alpha$-secretases that shed the ectodomain APPs $\alpha$ and preclude $A \beta$ generation. $A \beta$ accumulation and deposition in brain may be pathogenic and set into motion a series of events referred to collectively as the amyloid hypothesis of AD (Selkoe, 2001). Major support for this hypothesis comes from the identification and analysis of the effects of gene mutations identified in early-onset autosomal dominant familial AD (FAD). All known FAD mutations increase either $A \beta$ deposition in brain or the generation of $A \beta$ from $A P P$, in particular the more amyloidogenic $A \beta 42$. For example, the APP Swedish mutation (APPswe; K651N/M652L in 751 isoform numbering) enhances APP cleavage by $\beta$-secretase, resulting in increased $A \beta 40$ and $A \beta 42$ production (Citron et al., 1992; Perez et al., 1996).

The intracellular cytoplasmic C-terminus of APP is a site for multiple adaptor protein interactions that regulate its trafficking and metabolism. For example, the APP tail contains the AP-2/clathrin-coated pit consensus motif -GYENPTY - essential for internalization and trafficking of certain transmembrane proteins (Lai et al., 1998; Perez et al., 1999). This domain is unique in being absolutely conserved across species and APP family members, thus indicating its pivotal role in normal APP functions (Table 1). Mutation of both tyrosine residues in this sequence reduces APP internalization five-fold (Lai et al., 1998; Tomita et al., 1998). However, the critical motif for internalization of APP is the tetrapeptide -YENP - (Perez et al., 1999). The -GYENPTY - sequence also mediates interaction with phosphotyrosine binding (PTB) domain-containing partners such as the Fe65 and X11 families of adaptor 
Table 1. Multiple sequence alignment of the cytoplasmic domain of the APP family ${ }^{a}$

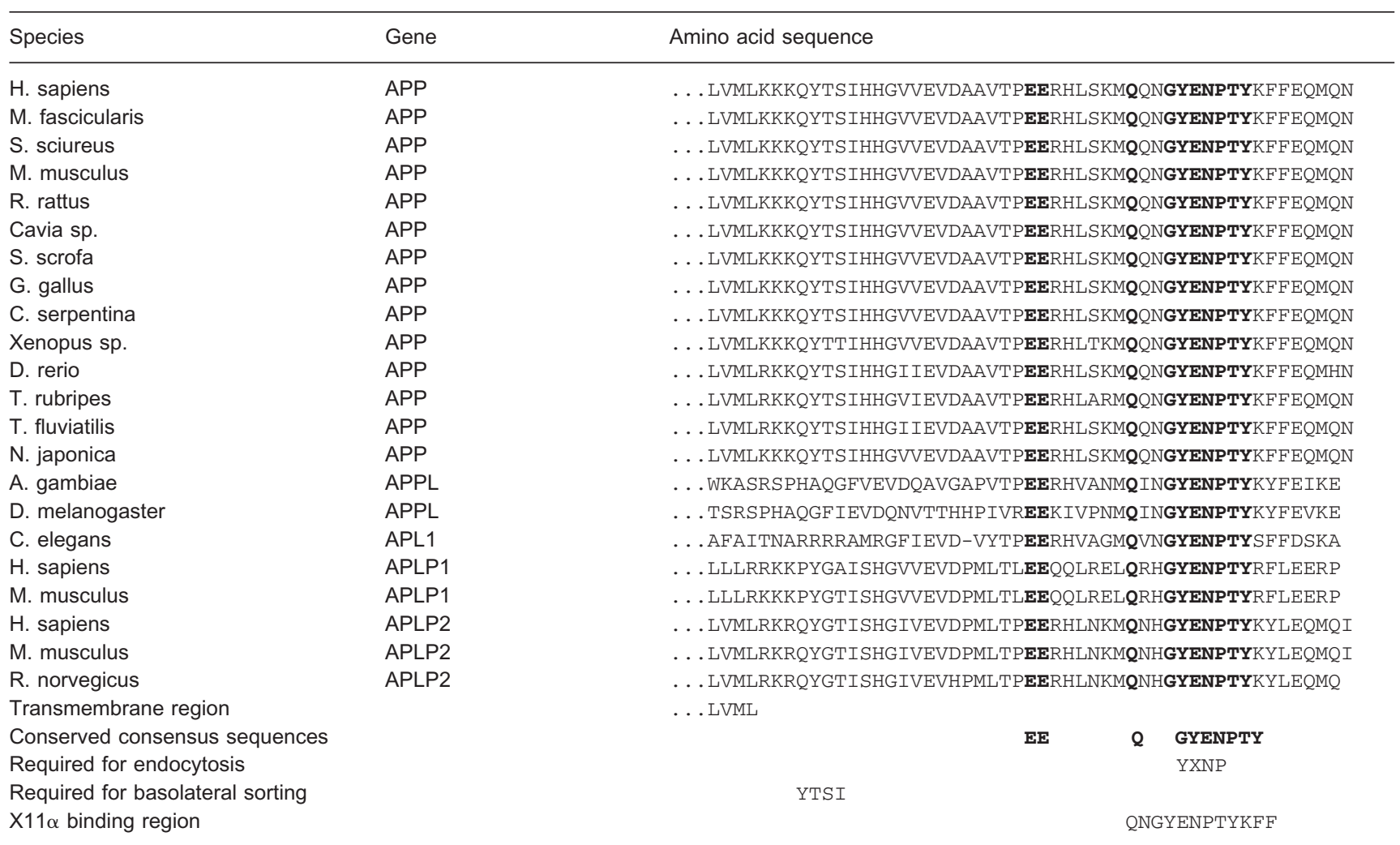

${ }^{a}$ Multiple sequence alignment revealed the uniquely conserved -YENPTY- motif in the cytoplasmic domains of the APP family. The -YENPTYsequence is a consensus motif for AP-2/clathrin-mediated endocytosis and contains the consensus for PTB domain-containing adaptor protein interactions. The -YXNP- motif of APP is required for endocytosis (Perez et al., 1999). The-YTSI- motif localized near the cell membrane is essential for basolateral targeting in polarized epithelial cells (Lai et al., 1998). The -YENPTY- motif also spans the X11 $\alpha$ binding region (Zhang et al., 1997). APLP1 and APLP2 are amyloid precursor protein like-1 and -2 .

proteins (Borg et al., 1996; Zambrano et al., 1998). Fe65 binding to APP accelerates its transit in the secretory pathway and promotes $A \beta$ secretion (Sabo et al., 1999). In contrast, $X 11 \alpha$ retards APP catabolism and inhibits $A \beta$ secretion (Borg et al., 1998b; Sastre et al., 1998; Mueller et al., 2000) by unclear mechanisms.

$\mathrm{X} 11 \alpha$ (also known as mint1 and lin-10) is one of three family members $(\mathrm{X} 11 \alpha, \beta$, and $\gamma)$ containing highly conserved C-terminal PTB and repeated sequences in Postsynaptic density-95 (PSD-95), D. melanogaster septate junction protein Disks-large, and epithelial tight junction protein Zona occludens-1 (PDZ) domains and divergent $\mathrm{N}$-terminal domains as well as divergent tissue distributions (Blanco et al., 1998; Butz et al., 1998; McLoughlin et al., 1998; Okamoto and Sudhof, 1998; Tanahashi and Tabira, 1999a,b). A munc-interaction domain present in $X 11 \alpha$ and $X 11 \beta$, but not $X 11 \gamma$, binds to munc- 18 , which is critical to synaptic vesicle exocytosis (Okamoto and Sudhof, 1997). A CASK interaction domain found in $\mathrm{X} 11 \alpha$, but not $X 11 \beta$ or $X 11 \gamma$, binds to CASK to form a heterotrimeric complex with Veli that targets certain transmembrane receptors in polarized cells (epithelia and neurons). For example, $\mathrm{X} 11 \alpha$ is essential for GLR-1 glutamate receptor localization to the postsynaptic membrane in neurons (Rongo et al., 1998). These findings suggest a role for
$\mathrm{X} 11 \alpha$ in transmembrane receptor targeting and tethering in polarized cells, and we propose a similar role for X11 $\alpha$ on APP trafficking and function in neurons. In mammalian brain the complex $\mathrm{X} 11 \alpha / \mathrm{CASK} /$ Veli is enriched at synaptic terminals (Borg et al., 1998a; Butz et al., 1998) but localizes mostly in perinuclear vesicular (membranous) compartments in neurons, which is identical to the localization of APP (Borg et al., 1999).

The specific conformational requirements for the APP: $\mathrm{X} 11 \alpha$ interaction are only partly mapped. Similarly, our knowledge of the key roles of the -YENPTY - motif in cellular APP trafficking and processing is incomplete. With wild type APP, the mutations APP Y738A or N740A inhibit $\mathrm{X} 11 \alpha$ binding and impair APP endocytosis (Borg et al., 1996; Sastre et al., 1998; Perez et al., 1999). APP P741A also impairs endocytosis (Perez et al., 1999) but the effect of this mutation on $\mathrm{X} 11 \alpha$ binding and $\mathrm{X} 11 \alpha$-mediated effects on APP metabolism are unknown. The APP Y743A mutation does not impair endocytosis or $\mathrm{X} 11 \alpha$ binding but increases APP half-life (Borg et al., 1996; Perez et al., 1999). The effects of $X 11 \alpha$ on APP $Y 743 A$ metabolism are also unknown. Although $A \beta$ secretion is consistently inhibited by $\mathrm{X} 11 \alpha$ coexpression with APP, the mechanism and localization of these $\mathrm{X} 11 \alpha$-mediated effects are unclear. Therefore, we explored the effects of point mutations in the 
-YENPTY - motif of APPswe, expressed alone or with $\mathrm{X} 11 \alpha$, on its trafficking and metabolism and report several novel observations.

\section{EXPERIMENTAL PROCEDURES}

\section{Cell culture}

Human embryonic kidney (HEK) 293 cells (American Type Culture Collection) were passaged in Dulbecco Modified Eagle medium (DMEM; Invitrogen) containing penicillin $(100 \mathrm{U} / \mathrm{ml})$ and streptomycin sulfate (Invitrogen) $(100 \mu \mathrm{g} / \mathrm{ml})$ supplemented with $10 \%$ fetal bovine serum (Atlanta Biologicals).

\section{DNA constructs}

Myc-tagged X11 $\alpha$ was cloned in pRK5 as described (Borg et al., 1996). APPswe ${ }_{751}$ and its C-terminal missense mutations were cloned into pcDNA3 as described (Perez et al., 1999). All constructs were created by a PCR method and sequenced using Sequenase Version 2.0 (U.S. Biochemical). The APP ${ }_{751}$ isoform and Swedish mutation (K651N/M652L; APPswe) in pcDNA3 were used to permit robust detection of both $A \beta 40$ and $A \beta 42$ in conditioned media, and to more closely mimic neuronal APP metabolism in non-neuronal HEK 293 cells (Forman et al., 1998).

\section{Cell transfection and protein extraction}

Six centimeter plates were precoated with poly-D-lysine (Sigma; $10 \mu \mathrm{g} / \mathrm{ml})$ prior to use. HEK 293 cells were plated $\left(7.5 \times 10^{5}\right.$ cells $/ 6$ $\mathrm{cm}$ plate) $24 \mathrm{~h}$ prior to transfection. Fifteen microliters of LipofectAMINE 2000 (Invitrogen) per plate was used to transfect $3 \mu \mathrm{g}$ of DNA for single transfections or $6 \mu \mathrm{g}$ of DNA for double transfections according to the manufacturer's instructions. Cells were maintained in serum-free OptiMem I (Invitrogen) for $6 \mathrm{~h}$ posttransfection. At $6 \mathrm{~h}$, OptiMem I containing $5 \%$ fetal bovine serum replaced the previous media and cells were further incubated for 24-48 h. Conditioned media were removed and centrifuged at $15,000 \times g$ for $10 \mathrm{~min}$ at $4{ }^{\circ} \mathrm{C}$ to remove cellular debris. After washing in PBS, cells were lysed with NP40 lysis buffer (50 mM Tris, $150 \mathrm{mM} \mathrm{NaCl}, 1 \% \mathrm{NP} 40,0.5 \%$ DOC, $0.1 \%$ SDS, $0.5 \mathrm{mM}$ EDTA) supplemented with phenylmethyl-sulfonylfluoride (Sigma) and complete protease inhibitor cocktail (Roche). Cell lysates were centrifuged at $15,000 \times \mathrm{g}$ for $10 \mathrm{~min}$ at $4{ }^{\circ} \mathrm{C}$.

\section{Immunoprecipitation}

To probe $\mathrm{X} 11 \alpha$ :APP interaction, $\mathrm{X} 11 \alpha$ was immunoprecipitated from cell lysates with anti-myc (9E10, Santa Cruz) followed by immunoblot of recovered proteins with the anti-APP antibody (22C11, Chemicon). APP or APPs were recovered from $1 \mathrm{ml}$ of cell lysate or conditioned media, respectively, by incubation with antibody to APP (Biosource) or APPs (Karen, a polyclonal serum raised to the N-terminus of APP) (Turner et al., 1996) and protein-A sepharose beads (Sigma) for $4 \mathrm{~h}$ at $4{ }^{\circ} \mathrm{C}$. Beads were then washed twice with wash buffer $(400 \mathrm{mM} \mathrm{NaCl}, 50 \mathrm{mM}$ Tris, $0.25 \%$ DOC, $0.25 \%$ NP40, pH 7.5). After boiling with sample buffer containing $\beta$-mercaptoethanol, recovered proteins were separated by $8 \%$ Tris-glycine sodium dodecyl sulfate-polyacrylamide gel electrophoresis (SDS-PAGE; Invitrogen), and detected by immunoblot.

\section{Immunoblotting}

Proteins were transferred from gels to polyvinyldiene difluoride (Roche) membranes presoaked in methanol. Membranes were blocked in 5\% milk in TBST. The monoclonal antibody 22C11 (Chemicon) raised to an N-terminal domain of APP (residues 61-88) was used to detect APP. Anti-myc (9E10, Santa Cruz) was used to confirm expression of myc-tagged $\mathrm{X} 11 \alpha$ constructs in cell lysates. ECL Plus (Amersham) detected horseradish peroxidaseconjugated goat anti-mouse (Chemicon) by Phosphorlmager analysis. Protein bands were quantitated with a STORM Scanner using ImageQuant software (Molecular Dynamics).

\section{Metabolic radiolabeling}

Twenty-four hours after transfection, cells were starved for $15 \mathrm{~min}$ in cysteine/methionine-free DMEM (Invitrogen). Subsequently, cells were incubated in DMEM containing $\left[{ }^{35}\right.$ S]methionine (ICN) for $1 \mathrm{~h}$ for pulse-labeling. Cells were then rinsed with PBS, lysed, and proteins immunoprecipitated as described above, using antiAPP antibody (Biosource). For pulse-chase experiments, cells were further incubated with DMEM containing excess unlabeled methionine for 0-8 h. Immunoprecipitated proteins were separated by $8 \%$ Tris-glycine SDS-PAGE, and radiolabeled bands detected by autoradiography and quantitated by Phosphorlmager analysis using a STORM Scanner with ImageQuant software (Molecular Dynamics).

\section{Uptake assay}

Triplicate cultures of cells transfected $24 \mathrm{~h}$ before (see above) were grown in 12 well tissue culture plates. We measured internalization of cell surface APP, as previously described (Perez et al., 1999) except with the 22C11 antibody (Chemicon). Antibody was iodinated using Chloramine-T (Perkin-Elmer) to approximately 3-6 $\mu \mathrm{Ci} / \mu \mathrm{g}$ as previously described (Perez et al., 1999) and added to binding medium (BM; RPMI 1640 supplemented with $20 \mathrm{mM}$ HEPES, $0.2 \%$ BSA; Invitrogen) before being applied to confluent layers of cells and incubated at $37^{\circ} \mathrm{C}$ for $30 \mathrm{~min}$. After incubation, cells were rapidly chilled on ice and the reaction was quenched by addition of ice cold BM. After $10 \mathrm{~min}$, chilled cells were washed multiple times with ice cold Dulbecco's Phosphatebuffered saline (Invitrogen) to eliminate unbound antibody. Residual antibody bound to APP (acid-labile fraction) was then detached from cell surfaces by two 5 min washes with ice cold PBS, $\mathrm{pH} 2.5$, and collected into sample tubes. Cells were lysed in $0.2 \mathrm{M}$ $\mathrm{NaOH}$ (acid-resistant fraction) and collected into sample tubes. Acid-labile and acid-resistant counts were measured by $\gamma$ counting. The ratio of acid-resistant to acid-labile counts provided a measure of internalized versus cell-surface pools of APP. Specific binding was calculated after subtraction of the radioactive counts obtained from labeled nontransfected cells.

\section{Secreted $\beta$-secretase cleavage product of APPswe (APPsßswe) enzyme-linked immunosorbent assay (ELISA)}

APPs $\beta$ swe in conditioned media was detected by a sandwich ELISA using 931 antiserum as the capture antibody (Steinhilb et al., 2001). This antiserum does not recognize full length APPswe, APPs $\alpha$ swe, APP, APPs $\alpha$, or APPs $\beta$, and is thus specific for the neoepitope in the C-terminus of APPs $\beta s w e$. The affinity purified capture antibody was diluted to $1.2 \mu \mathrm{g} / \mathrm{mL}$ in PBS and $100 \mu \mathrm{l} /$ well added to a 96 well Nunc-Immuno Maxisorp plate (Nalge Nunc International). Twenty-five microliters of conditioned media/well were aliquotted in triplicate and the following day wells were incubated with $100 \mu$ l of diluted detector antibody (mouse monoclonal antibody mAbP2-1, Biosource) at $0.25 \mu \mathrm{g} / \mathrm{ml}$. Lastly, wells were incubated for $1 \mathrm{~h}$ with horseradish peroxidase-conjugated rabbit anti-mouse IgG (1:4000; Southern Biotechnology Associates, Inc.). TMB solution (Pierce Chemicals) and $2 \mathrm{M}$ sulfuric acid were used to detect bound antigen in wells by measuring absorbance at $450 \mathrm{~nm}$ spectrophotometrically. 


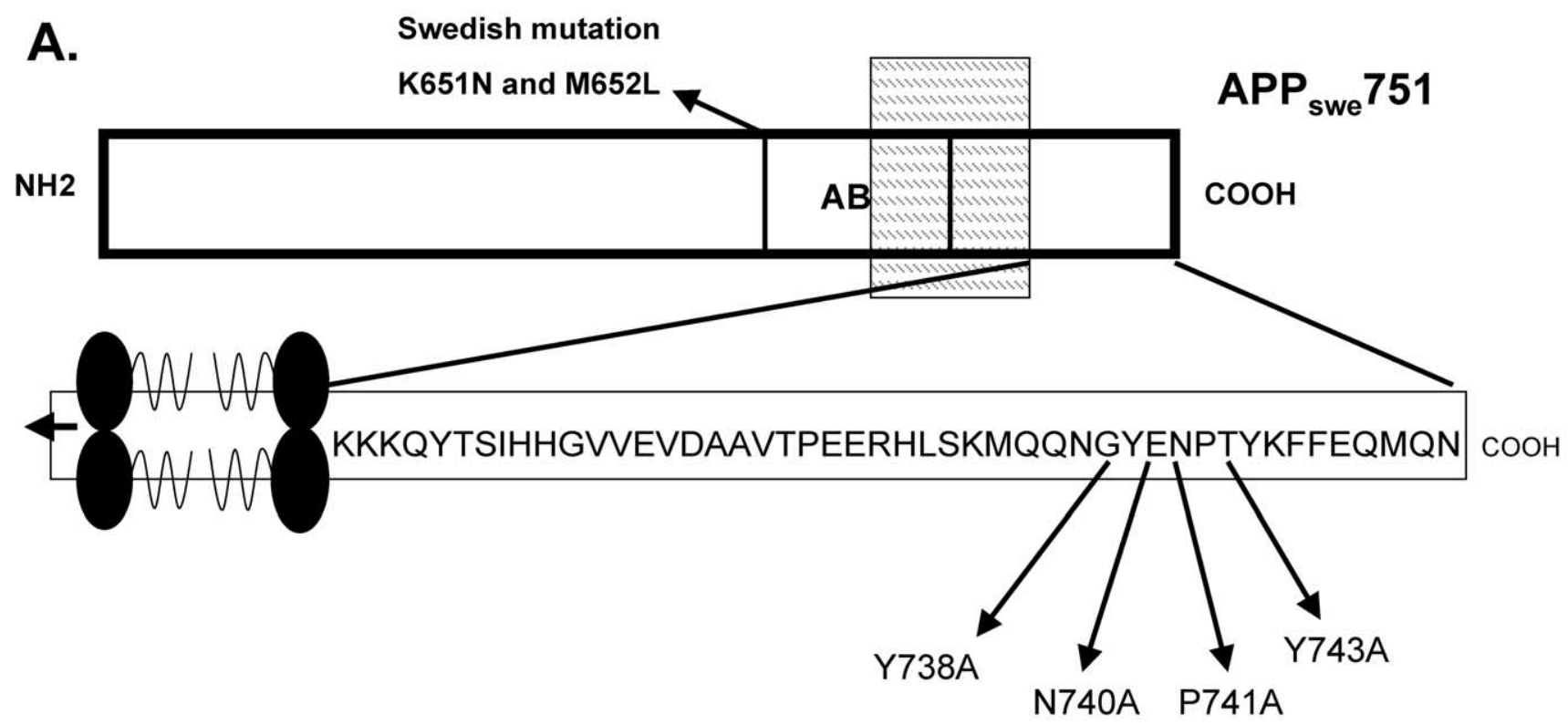

\section{B. $\mathbf{X 1 1} \alpha$}

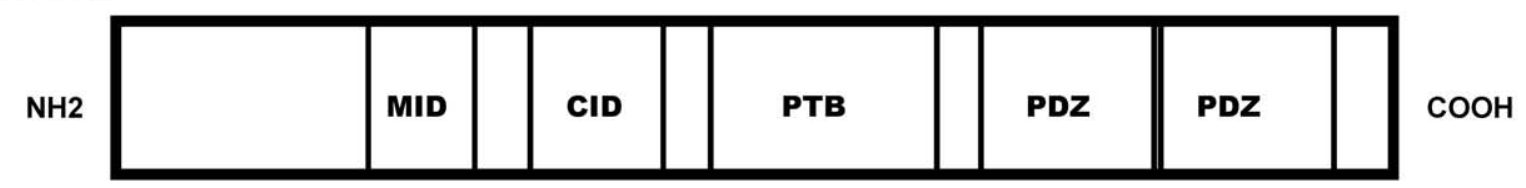

Fig. 1. Schematic representations of APPswe, its C-terminal missense mutations studied herein, and the protein interaction domains of $X 11 \alpha$. (A) The Swedish mutation of APP (APPswe; K651N/M652L) was used in these studies. The missense mutations generated within the - YENPTY - motif of APPswe are also indicated. AB indicates the A $\beta$ sequence within APP. (B) X11 $\alpha$ contains a Munc18-interacting domain (MID, residues 226-314), a CASK/lin-2 interacting domain (CID, residues 373-436), a PTB/protein interaction domain (residues 457-643) and two PDZ domains (residues 656-742 and 747-822).

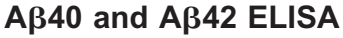

$A \beta 40$ and $A \beta 42$ in conditioned media were detected by a sensitive and specific sandwich ELISA (Suzuki et al., 1994; Turner et al., 1996; Borg et al., 1998b; Mueller et al., 2000). BAN50 was used as the capture antibody and either horseradish peroxidase-coupled $\mathrm{BA}-27$ or $\mathrm{BC}-05$ as the detection antibody for $\mathrm{A} \beta 40$ or $\mathrm{A} \beta 42$, respectively. BAN-50 is a monoclonal antibody specific for $A \beta 1$ 10. Standard curves were generated for $A \beta 40$ and $A \beta 42$ (Bachem) for quantitation.
\end{abstract}

\section{Statistical analysis}

Significant differences between means were determined by multiple analyses of variance using a Student's $t$-test.

\section{RESULTS}

The -YENP - motif of APPswe is essential for $\mathrm{X} 11 \alpha$ interaction

Our previous data (Borg et al., 1998) suggested that the -YENP - internalization motif, not the -NPTY - sequence, was essential for the PTB domain of $X 11 \alpha$ to bind APP. To further define the specific conformational requirements of the X11 1 :APP interaction, HEK 293 cells were transfected with APPswe or its C-terminal point mutations (Fig. 1A, B). To probe in vitro interaction, $\mathrm{X} 11 \alpha$ was immu- noprecipitated from cell lysates and binding to APPswe mutants was determined by immunoblot. X11 $\alpha$ interacted with APPswe and APPswe Y743A, much less with APPswe Y738A, but not with APPswe N740A or APPswe P741A (abbreviated as Y738A, N740A, P741A, and Y743A hereafter; Fig. 2B). These data indicated that the $-Y X N P$ - tetrapeptide motif was essential for $\mathrm{X} 11 \alpha$ binding, and therefore likely to be essential for X11 $\alpha$-mediated modulation of APP trafficking and metabolism.

\section{$\mathrm{X} 11 \alpha$ retards maturation of APPswe and APPswe Y743A}

To probe the metabolic effects of the APPswe YENPTY mutations, with and without $\mathrm{X} 11 \alpha$, we examined APP and its catabolites in cell lysates and conditioned media. X11 $\alpha$ coexpression increases the relative level of APPswe in cell lysates (Borg et al., 1996; Mueller et al., 2000) and also increased the cellular level of $Y 743 A$, but had no effect on Y738A, N740A, or P741A (Fig. 3A, C). These results are consistent with the interaction assay (Fig. 2), and also revealed the lack of nonspecific effects of $\mathrm{X} 11 \alpha$ on the catabolism of APPswe mutants that were incapable of binding to $\mathrm{X} 11 \alpha$. Equivalent levels of $\mathrm{X} 11 \alpha$ expression were confirmed by immunoblot (Fig. 3B). When mature 

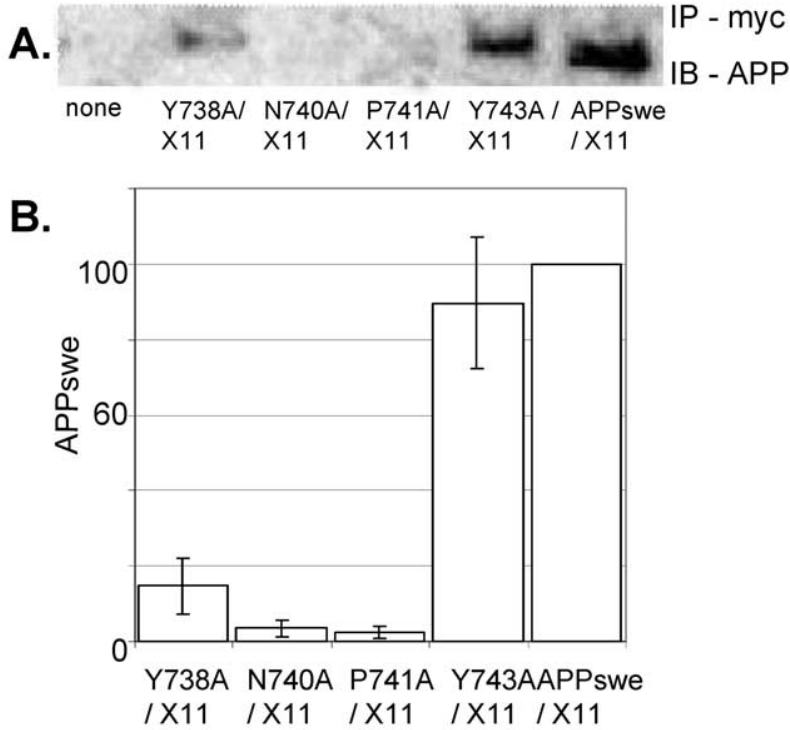

Fig. 2. $\mathrm{X} 11 \alpha$ requires the $-\mathrm{YENP}-$ motif of APPswe for binding. (A) Representative immunoblot of APPswe and the APPswe mutations indicated recovered from transiently transfected HEK 293 cells. Proteins in cell lysates were immunoprecipitated with anti-myc (9E10) to recover $\mathrm{X} 11 \alpha$ and bound APPswe or its mutations were subsequently detected by immunoblot (with 22C11). (B) Semi-quantitative analysis of levels of APPswe or mutations as determined with a Phosphorlmager. Data were normalized to APPswe (set as $100 \%), n=4$.

(post-translationally modified, $\mathrm{N}$-glycosylated and O-glycosylated APP; Weidemann et al., 1989; Oltersdorf et al., 1990) versus immature (i.e. not fully glycosylated) APPswe were examined separately, $\mathrm{X} 11 \alpha$ inhibited maturation of APPswe and Y743A, but not the endocytic-defective mutants Y738A, N740A, or P741A (Fig. 3A, D). Collectively, these data revealed that point mutations within the -YENP - sequence of APPswe blocked X11 $\alpha$ binding to APPswe and consequently the effects of $X 11 \alpha$ on APPswe metabolism, suggesting that this motif normally contributes to APP/X11 $\alpha$ interactions. Like APPswe, Y743A bound to $X 11 \alpha$ and therefore its maturation and metabolism were affected. Based on quantitative differences in the levels of mature versus immature APPswe, the impairment of APPswe and $Y 743 A$ maturation suggests that $X 11 \alpha$ retarded their egress through the secretory compartment, specifically by retarding their transit between the ER and trans Golgi. Interestingly, we observed less mature than immature $\mathrm{Y} 743 \mathrm{~A}$ in cells cotransfected with $\mathrm{X} 11 \alpha$, suggesting that those cells would have less full length APPswe at the cell surface.

\section{X11 $\alpha$ prolongs the half-life of APPswe and APPswe Y743A}

To further test the hypothesis that an interaction between $\mathrm{X} 11 \alpha$ and APPswe may alter its catabolism, we performed metabolic radiolabeling experiments to determine the effects of $X 11 \alpha$ coexpression on the half-life of APPswe, Y743A, or N740A. For these experiments, N740A was selected as representative of the endocytic-defective mutations. $\mathrm{X} 11 \alpha$ coexpression doubled the half-life of APP- swe to approximately $1.5 \mathrm{~h}$ (Fig. 4A), which is similar to X11 $\alpha$ 's effect on wild type APP (Borg et al., 1998b; Sastre et al., 1998). The Y743A mutation alone had a unique effect in prolonging half-life (Fig. 4C), and coexpression with $\mathrm{X} 11 \alpha$ further prolonged its half-life to $>4 \mathrm{~h}$ (Fig. $4 \mathrm{C}$ ). These data indicated that a point mutation of the -NPTYtyrosine when coexpressed with $\mathrm{X} 11 \alpha$ exaggerated the effects of Y743A on APP trafficking and metabolism similar to our earlier studies (Perez et al., 1999; Fig. 4C). In contrast, the N740A mutation did not significantly affect half-life, and $X 11 \alpha$ coexpression with N740A had no effect, as predicted (Fig. 4B). For all APP constructs the results obtained at $8 \mathrm{~h}$ of chase (data not shown) were similar to those observed at $4 \mathrm{~h}$. These data are consistent with previous results suggesting that $\mathrm{X} 11 \alpha$ modulated the metabolism of APPswe and Y743A, but not of N740A.

\section{X11 $\alpha$ inhibits secreted metabolites from APPswe with an intact - YENP - sequence}

We next measured the effects of the APPswe YENPTY mutations, expressed with and without $X 11 \alpha$, on secreted metabolites of APPswe (measured from conditioned media of cells transfected to obtain the results in Fig. 3). Compared with APPswe alone, Y743A increased and N740A decreased total APPs secretion (Fig. 5A), while Y738A or P741A had less of an effect. These studies using APPswe are in contrast to our studies using wild type APP in which -YENP - internalization-defective mutants increase APPs secretion (Perez et al., 1999). This difference may reflect the fact that endocytic processing is the predominant catabolic pathway of APP whereas catabolism of APPswe with or without -YENP - mutations occurs predominantly in the secretory pathway. We previously observed that cells overexpressing APPswe produce significantly more $A \beta$ in both the secretory and endocytic pathways (Perez et al., 1996). X11 $\alpha$ decreased APPs secretion when coexpressed with APPswe or Y743A, but not with Y738A, N740A or P741A (Fig. 5A) as expected from our observation that these mutants interact very little with $\mathrm{X} 11 \alpha$. These results further demonstrated that mutations within the -YENP - sequence, but not of the NPTY tyrosine (Y743) abolished $\mathrm{X} 11 \alpha$-mediated effects on APP catabolism.

In addition, we developed a novel ELISA to specifically detect the neoepitope at the C-terminus of APPs $\beta$ swe, that does not detect wild type APPs $\alpha$ or APPs $\beta$, or APPs $\alpha$ swe (Steinhilb et al., 2001). This ELISA allowed us to analyze the effect of APP C-terminal mutations, expressed with or without $X 11 \alpha$, on $\beta$-secretase activity. Similar to the findings with total APPs, Y743A also increased and N740A decreased APPs $\beta$ swe secretion compared with APPswe alone. Coexpression of $X 11 \alpha$ with $Y 743 A$, but not with APPswe, inhibited secretion of APPs $\beta s w e$ (Fig. $5 B$ ), again demonstrating a unique metabolism of $Y 743 A$ probably associated with its extremely long half-life. X11 $\alpha$ inhibits $A \beta 40$ and $A \beta 42$ secretion upon coexpression with APPswe (Borg et al., 1998b; Mueller et al., 2000). X11 $\alpha$ also inhibited $A \beta 40$ and $A \beta 42$ secretion when coexpressed with Y743A but not with Y738A, N740A, or P741A (Fig. 5C, D). Collectively, these data suggested specific inhibition of $\gamma$ - 

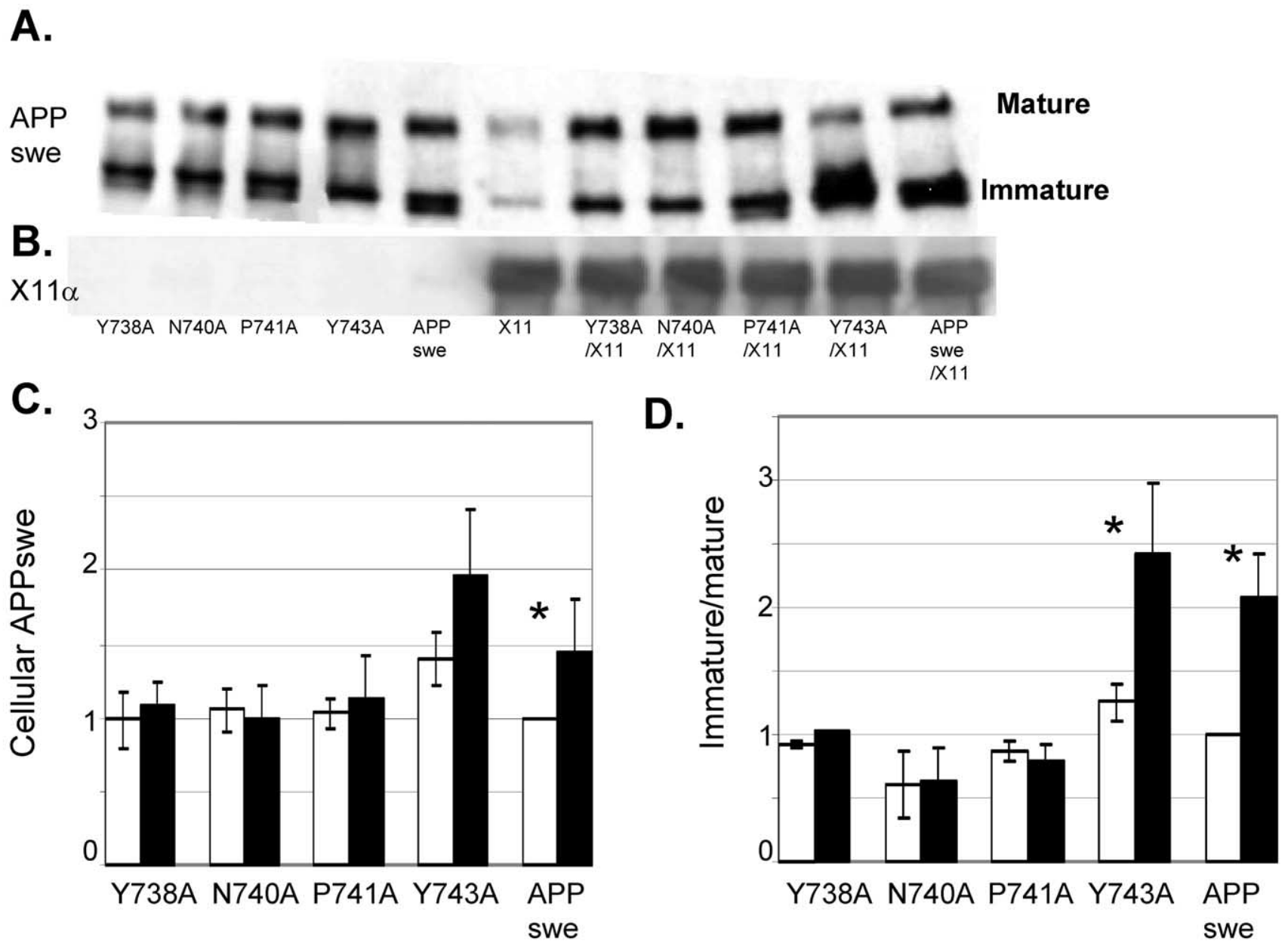

Fig. 3. X11 $\alpha$ interaction retards APPswe and Y743A maturation. (A) HEK 293 cells were transiently transfected with the APPswe constructs indicated, with or without $\mathrm{X} 11 \alpha$. After $24 \mathrm{~h}$ of incubation, cells were lysed and proteins separated by $8 \%$ Tris-glycine SDS-PAGE. APPswe was detected by immunoblot (with 22C11) of separated proteins. Immature and mature indicate nascent and post-translationally modified (higher Mr) APPswe, respectively. (B) The immunoblot for X11 $\alpha$ (with 9E10) confirmed its equivalent expression. (C) Quantitation of total APPswe in cell lysates, as shown in A, relative to APPswe expression alone. (D) Ratio of immature to mature APPswe in cell lysates, relative to APPswe. Protein bands were quantitated with a Molecular Dynamics STORM Scanner. White bars indicate transfection with APPswe or the APPswe mutations alone, and black bars represent their cotransfection with $\mathrm{X} 11 \alpha$. The data shown are mean \pm S.E.M; * indicates $P \leq 0.05 ; n=5$.

but not $\beta$-cleavage of APPswe by $\mathrm{X} 11 \alpha$, since $A \beta$ but not APPs $\beta$ swe secretion was inhibited when $X 11 \alpha$ was coexpressed (Fig. 5B-D). In contrast to APPswe, however, with Y743A both $\beta$ - and $\gamma$-cleavage of APPswe were inhibited by $\mathrm{X} 11 \alpha$.

\section{$\mathrm{X} 11 \alpha$ inhibits endocytosis of cell surface APP}

$\mathrm{X} 11 \alpha$ normally interacts with the -YENP - internalization motif of APP suggesting a role for $X 11 \alpha$ in endocytic processing of APP, but such a role has not yet been demonstrated. To test the hypothesis that $X 11 \alpha$ affects internalization of APP, we utilized a cell surface labeling method (iodinated anti-APP antibody 22C11) in cells transiently transfected with APPswe with and without $\mathrm{X} 11 \alpha$. YENP mutations were not evaluated since binding to $X 11 \alpha$ is not significant and we have previously described their role in APP endocytosis (Perez et al.,
1999). Likewise the Y743A mutation was not evaluated due to concerns stated above of a very small fraction reaching the cell surface. Compared with APPswe, $\mathrm{X} 11 \alpha$ coexpression significantly diminished uptake of cell-surface APPswe (Fig. 6). Thus, these data are consistent with the notion that $X 11 \alpha$ binding to APPswe retarded its internalization from the cell surface and therefore endocytic processing.

\section{DISCUSSION}

We describe several novel observations on the regulation of APPswe trafficking and metabolism by interaction with $X 11 \alpha: 1)$ the APPswe Y743A mutation produced unique effects on its metabolism, 2) the -YXNP - tetrapeptide was essential for $\mathrm{X} 11 \alpha$ binding and thus $\mathrm{X} 11 \alpha$-mediated effects on APPswe processing, 3) X11 $\alpha$ coexpression impaired maturation of APPswe and APPswe Y743A, and 4) 
A.

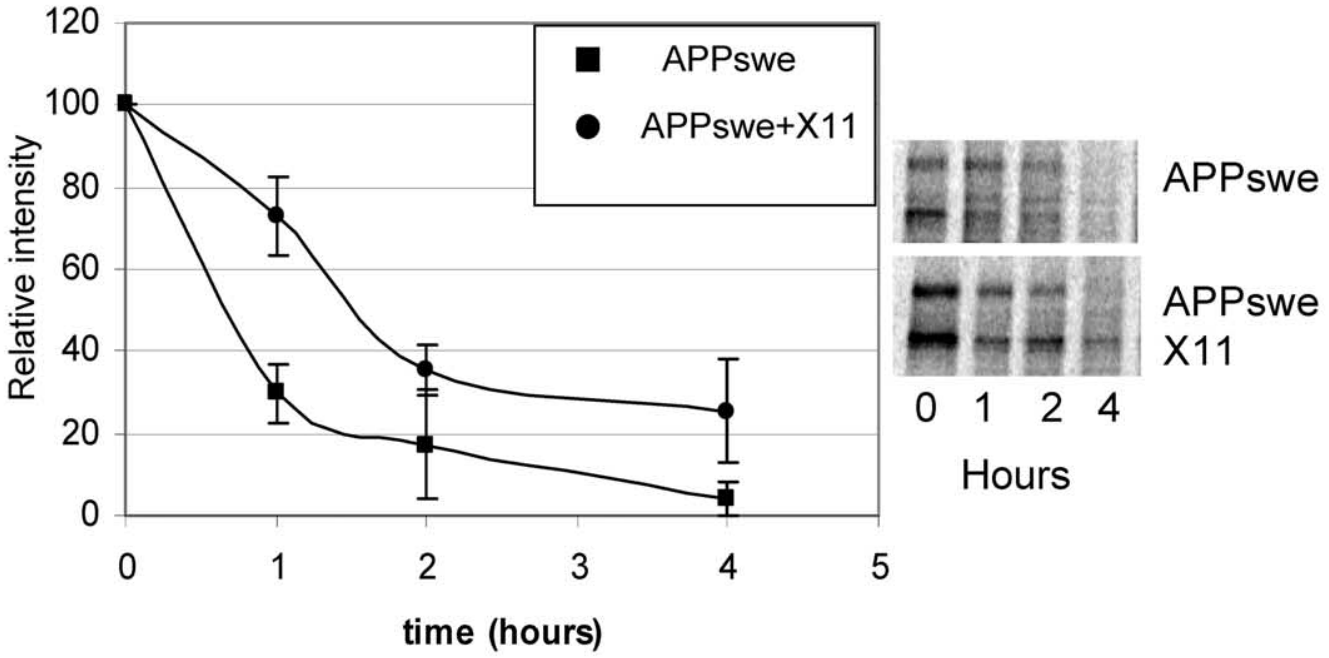

B.
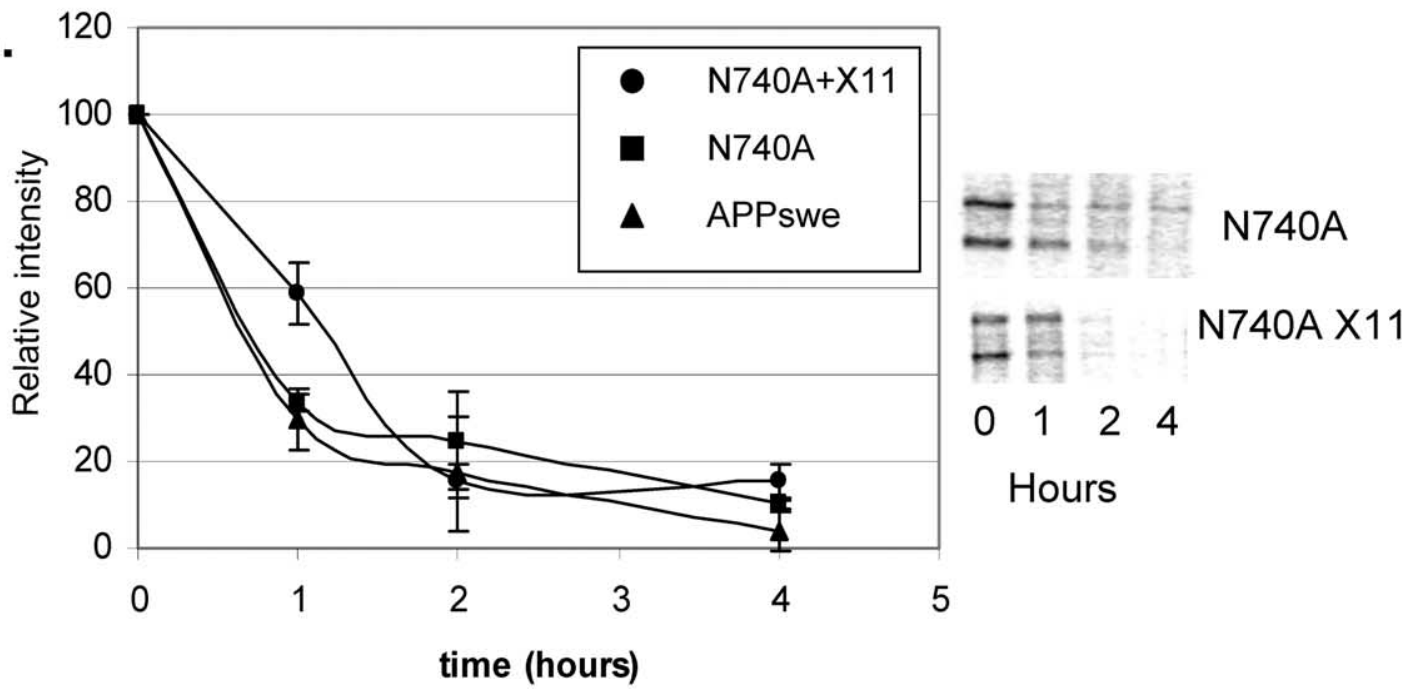

$0 \quad 124$

Hours

C.
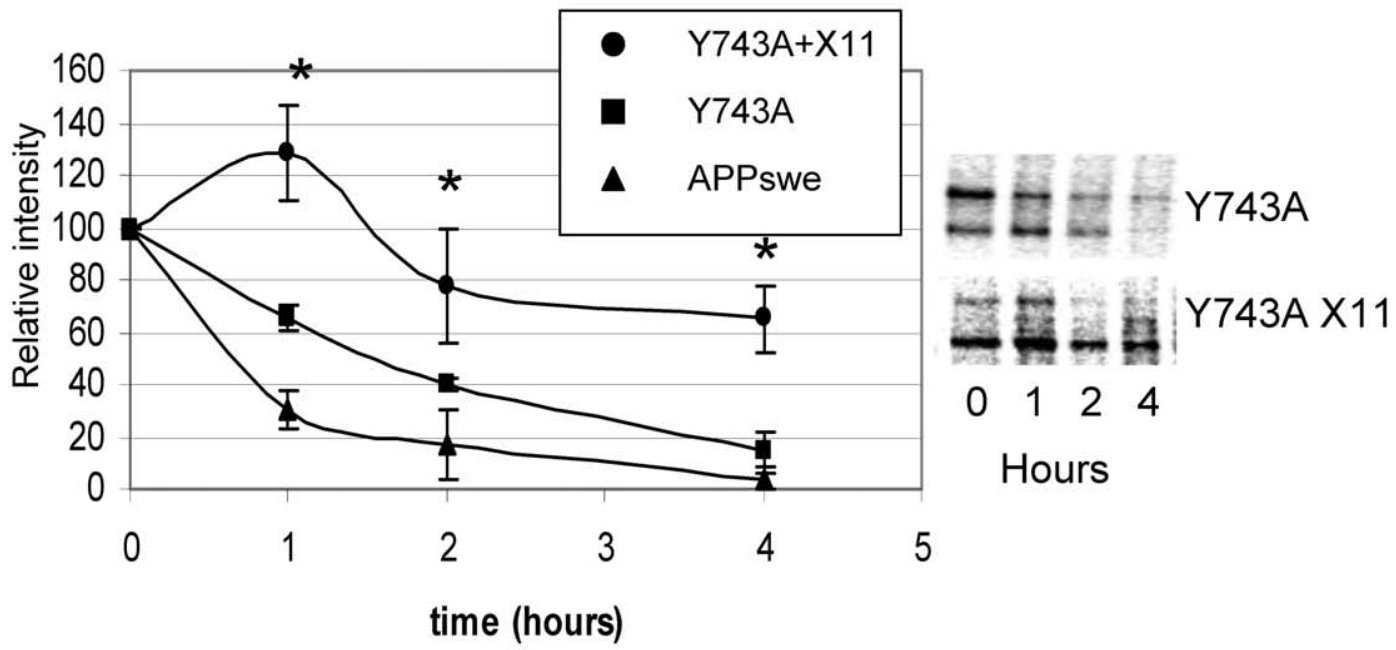

Hours

Fig. 4. X11 $\alpha$ prolongs APPswe and Y743A half-life. HEK 293 cells were transfected $24 \mathrm{~h}$ before metabolic radiolabeling with $\left[{ }^{35} \mathrm{~S}\right] \mathrm{methionine}$ for $1 \mathrm{~h}$ followed by a $0-4-h$ chase with excess unlabeled methionine. APPswe in cell lysates was immunoprecipitated (Biosource), separated by $8 \%$ Tris-glycine SDS-PAGE, and total APPswe (mature and immature) was quantitated with a Molecular Dynamics STORM Scanner and ImageQuant software. Pulse-chase data of (A) APPswe, (B) APPswe N740A, and (C) APPswe Y743A, with and without X11 $\alpha$, are indicated. Data shown are mean \pm S.E.M; * indicates $P \leq 0.05 ; n=5$. 

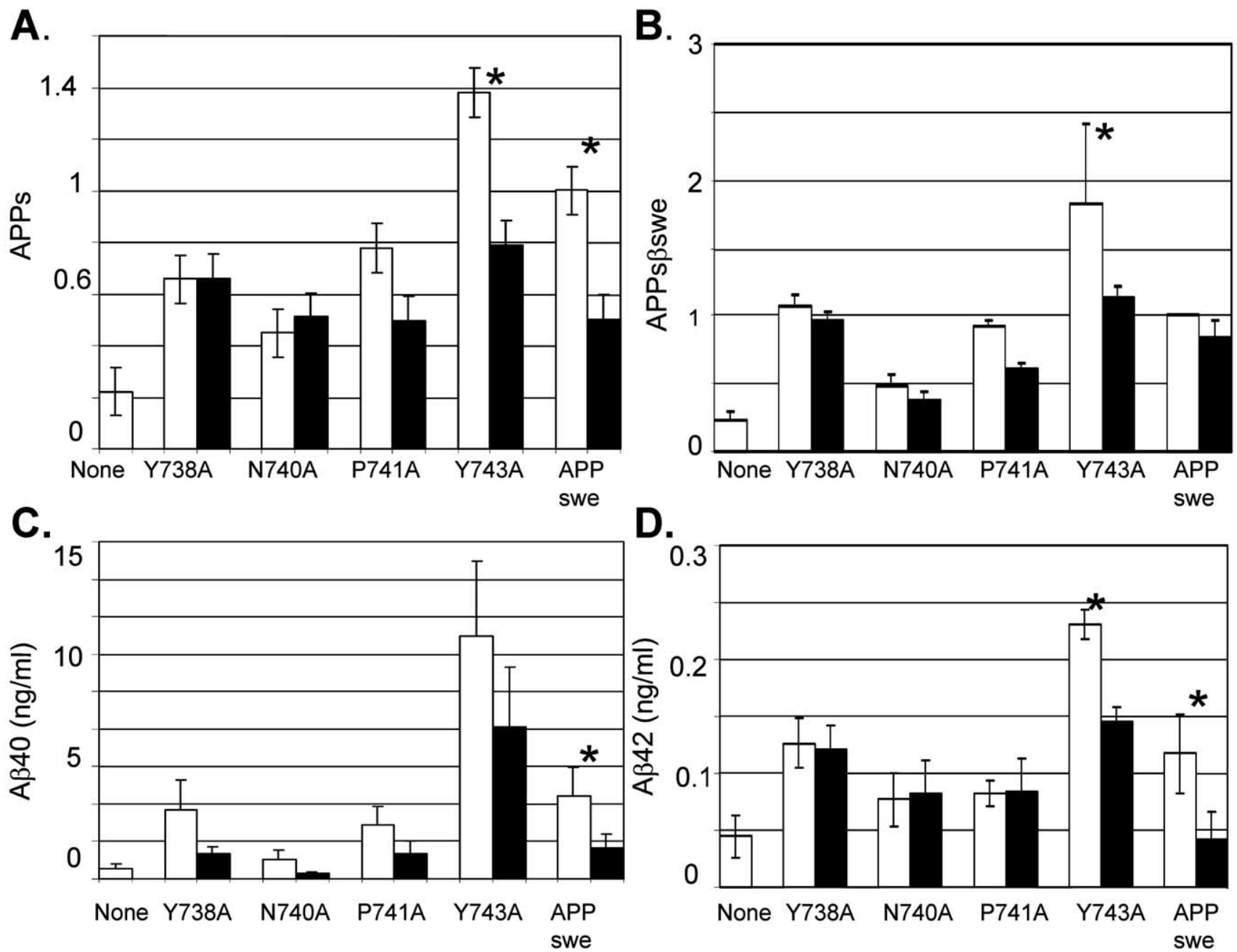

D.

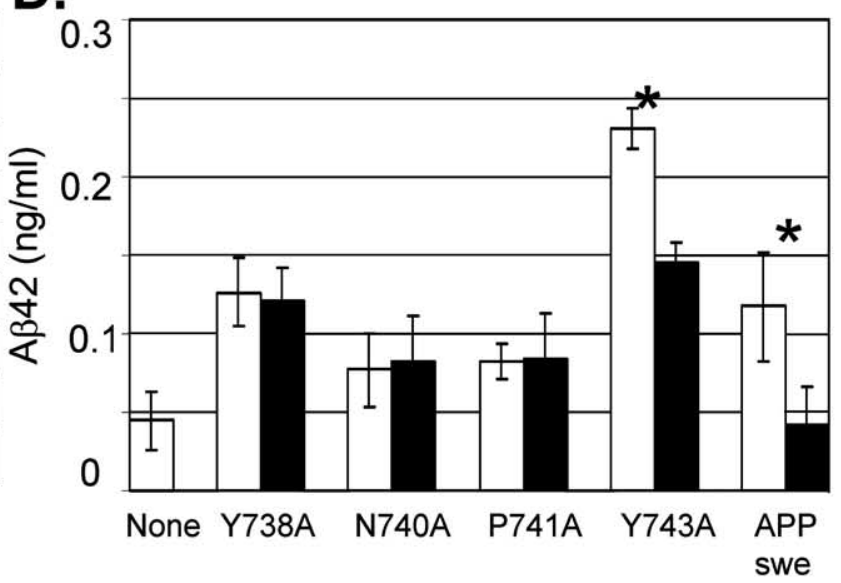

Fig. 5. Effects of $X 11 \alpha$ on APPs, APPs $\beta$ swe, $A \beta 40$, and $A \beta 42$ secretion. HEK 293 cells were transiently transfected as indicated and incubated for $48 \mathrm{~h}$. White bars represent APPswe or its mutations transfected alone, and black bars represent their cotransfection with $\mathrm{X} 11 \alpha$. Samples from conditioned media were subject to specific sandwich ELISA for (B) APPs $\beta s w e,(C) A \beta 40$, and (D) A $\beta 42$. For (C) and (D), absorbance was converted to concentration $(\mathrm{ng} / \mathrm{ml})$ using standard curves. For (A), total APPs was immunoprecipitated with Karen, immunoblotted with $22 \mathrm{C} 11$, and quantitated by Phosphorlmager analysis. The amount of APPs secreted by APPswe-transfected cells was set to $100 \%$. Data shown are mean \pm S.E.M; * indicates $P \leq 0.05 ; n=5-6$.

$\mathrm{X} 11 \alpha$ coexpression decreased uptake of cell-surface APPswe. These results suggest that the structural requirements for APP endocytosis and X11 $\alpha$-mediated effects of APPswe metabolism may be identical. In other words, the -YENP - motif may serve as either a retention signal or an endocytic signal for APP depending on differential and competitive adaptor protein interactions. We observed that $\mathrm{X} 11 \alpha$ modulates APPswe trafficking and metabolism in both the secretory and endocytic compartments (as summarized in Fig. 7). Because X11 $\alpha$ had little or no effect on internalization-defective mutations of APPswe, we could not dissect the structural requirements for APP endocytosis (Perez et al., 1999) away from the requirements for $\mathrm{X} 11 \alpha$ :APPswe binding and effects on APPswe trafficking and metabolism. $\mathrm{X} 11 \alpha$ retarded both APPswe maturation and internalization, suggesting that $X 11 \alpha$ may inhibit $A \beta 40$ and $A \beta 42$ generation in either the secretory or endocytic compartments.
The absolutely conserved -YENPTY - motif in the C-termini of the APP gene family suggests a key role for this motif in trafficking, processing, and function. Tyrosine residues, in particular, are pivotal in the regulation of protein trafficking. Mutation of both tyrosine residues in the -GYENPTY - sequence markedly impairs APP endocytosis (Cescato et al., 2000). Mutation of the tyrosine residue within the sequence -YTSI- near the cell membrane abolishes basolateral sorting of APP in polarized cells (Bayer et al., 1999). Mutation of all three tyrosine residues within the -YTSI- and -GYENPTY - motifs impairs lysosomal targeting of APP (Lai et al., 1998) but this targeting appears to be mainly due to the distal tyrosine in the motif as we previously observed for wild type APP (Perez et al., 1999). Mutation of any residue in the -YENPsequence significantly reduces APP endocytosis and inhibits A $\beta$ secretion in wild type APP (Perez et al., 1999). We now extend these observations by mapping the inter- 


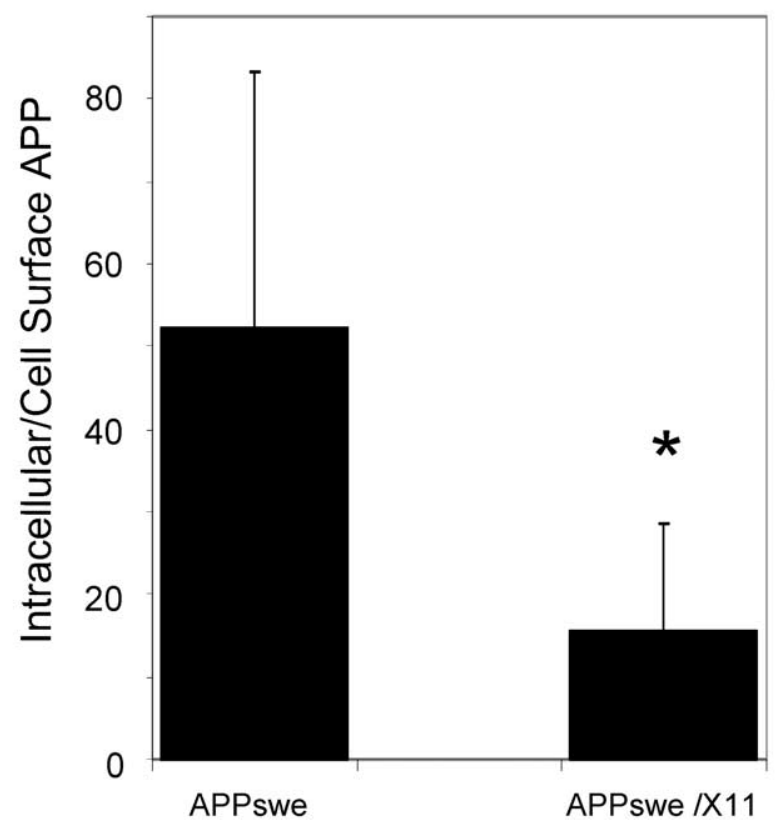

Fig. 6. X11 $\alpha$ impairs APPswe internalization. HEK 293 cells were transiently transfected with APPswe alone or with $\mathrm{X} 11 \alpha$ and incubated with [125]l-labeled anti-APP (22C11) for $30 \mathrm{~min}$ at $37^{\circ} \mathrm{C}$. Cell surface protein was measured by acid strip of cell surface proteins. lodinated intracellular protein was measured after subsequent cell lysis. Data shown are mean \pm S.E.M; * indicates $P \leq 0.05$ as calculated by MannWhitney test.

action requirement for $\mathrm{X} 11 \alpha$ to the $-\mathrm{YENP}-$ motif, and report for the first time the unique effects of the $Y 743 A$ mutation on APPswe metabolism.

The PTB-domain binding proteins are recruited to the sequence -NPXpY - when the distal tyrosine residue is phosphorylated, thus mediating receptor tyrosine kinasesignal transduction pathways. When the distal tyrosine, Y743 in the - NPXY - sequence of APP is phosphorylated, the affinity of $X 11 \alpha$ binding is unaffected (Zhang et al., 1997) whereas the binding of Dab1 is markedly impaired (Howell et al., 1999). Similar to the requirements for APP endocytosis (Perez et al., 1999) $X 11 \alpha$ interaction requires the -YXNP - and not the -NPXY - motif. Thus, phosphorylation of $Y 743$ would be unlikely to regulate the APP interaction with $\mathrm{X} 11 \alpha$ in vivo. In contrast, phosphorylation of $Y 738$ by the non-receptor tyrosine kinase abl generates the - pYXXP - motif recognized by SH2-containing adaptor proteins such as shc, abl, and Grb2 (Zambrano et al., 2001; Russo et al., 2002; Tarr et al., 2002). Phosphorylation of Y738 in APP may promote its interaction with SH2domain containing adaptor proteins and simultaneously preclude its interaction with PTB-containing adaptors such as the $\mathrm{X} 11$ and Fe65 families. Thus, tyrosine phosphorylation may modulate APP trafficking, metabolism, and function by regulating the interaction of APP with different adaptor proteins.

There are several known interaction partners of the APP cytoplasmic tail (Okamoto et al., 1995, 1996; Trommsdorff et al., 1998; Zheng et al., 1998; Homayouni et al., 1999; Chen et al., 2000; Kamal et al., 2000; Yu et al., 2000;
Gao and Pimplikar, 2001; Gunawardena and Goldstein, 2001; Matsuda et al., 2001; Scheinfeld et al., 2002), and all of these likely regulate APP trafficking and processing. While the X11 family retards APP catabolism and A $\beta$ secretion (Borg et al., 1998b; Sastre et al., 1998; Mueller et al., 2000) the Fe65 family has opposite effects (Guenette et al., 1999; Sabo et al., 1999). Since both families interact with the APP C-terminus via a PTB domain, these opposing effects on APP metabolism may be mediated by their distinct sets of protein interaction domains. For example, the WW domain of Fe65 interacts with mena and the actin cytoskeleton; the non-APP interacting PTB domain of Fe65 binds to the LRP family of lipoprotein receptors (Trommsdorff et al., 1998) or to the transcription factor CP2/LSF/LBP1 (Zambrano et al., 1998). It is unknown whether $\mathrm{X} 11 \alpha$ interacts with LRP. Fe65 enhances the effect of APP in acceleration of cell migration, perhaps by regulation of the amount of cell surface APP (Sabo et al., 2001). Fe65 may also stabilize and translocate the Cterminus of APP remaining after $\gamma$-secretase cleavage (the AICD, or APP intracytoplasmic domain) to the nucleus in a Notch-like manner, and thus regulate gene transcription (Cao and Sudhof, 2001; Cupers et al., 2001; Kimberly et al., 2001). Similar to opposing effects on APP catabolism, and perhaps because of this, $\mathrm{X} 11 \alpha$ may have an opposite effect of Fe65 on this putative novel function of APP (Biederer et al., 2002).

Due to its localization and putative interaction partners, roles for $\mathrm{X} 11 \alpha$ in pre- and post-synaptic structure and function are suggested in mammalian brain. The munc18interaction, CASK-interaction, and PTB domains of X11 $\alpha$ are specific with regard to their binding partners. However, the PDZ domains are promiscuous and interact with multiple partners, including presenilin-1 (Lau et al., 2000), a presynaptic voltage-gated calcium channel (Maximov et al., 1999), spinophilin/neurabin II (Ide et al., 1998), the copper chaperone of SOD1 (McLoughlin et al., 2001), the dendritic kinesin KIF-17 (and via X11 $\alpha /$ CASK/Veli the $N$ methyl-D-aspartate receptor; Setou et al., 2000) and potentially with itself by dimerization of PDZ domains (Walhout et al., 2000). Many of these interaction partners mediate synaptic functions, again implying a scaffolding/ adaptor role for $\mathrm{X} 11 \alpha$ in the pre- and post-synaptic complex. In agreement with this hypothesis, X11 $\alpha$ knockout mice exhibit impaired dopaminergic (Hase et al., 2002) and GABAergic neurotransmission (Ho et al., 2003).

We recognize the limitations of our study using transient transfection of APPswe in non-neuronal cells; however, our conclusions may extrapolate to the trafficking and metabolism of APP in neurons in vivo. $\mathrm{X} 11 \alpha$ is expressed primarily in CNS neurons, and non-neuronal models of APP often extrapolate to neurons. APP:X11 $\alpha$ proteins colocalize in non-neuronal cells and neurons, and this complex occurs in mouse brain homogenates, supporting a role for $\mathrm{X} 11 \alpha$ in APP trafficking, metabolism, and function in neurons. Because of greater $\beta$-secretase expression in neurons and more efficient cleavage of APPswe by $\beta$-secretase (compared with wild type APP) the metabolism of APP in neuronal cells 


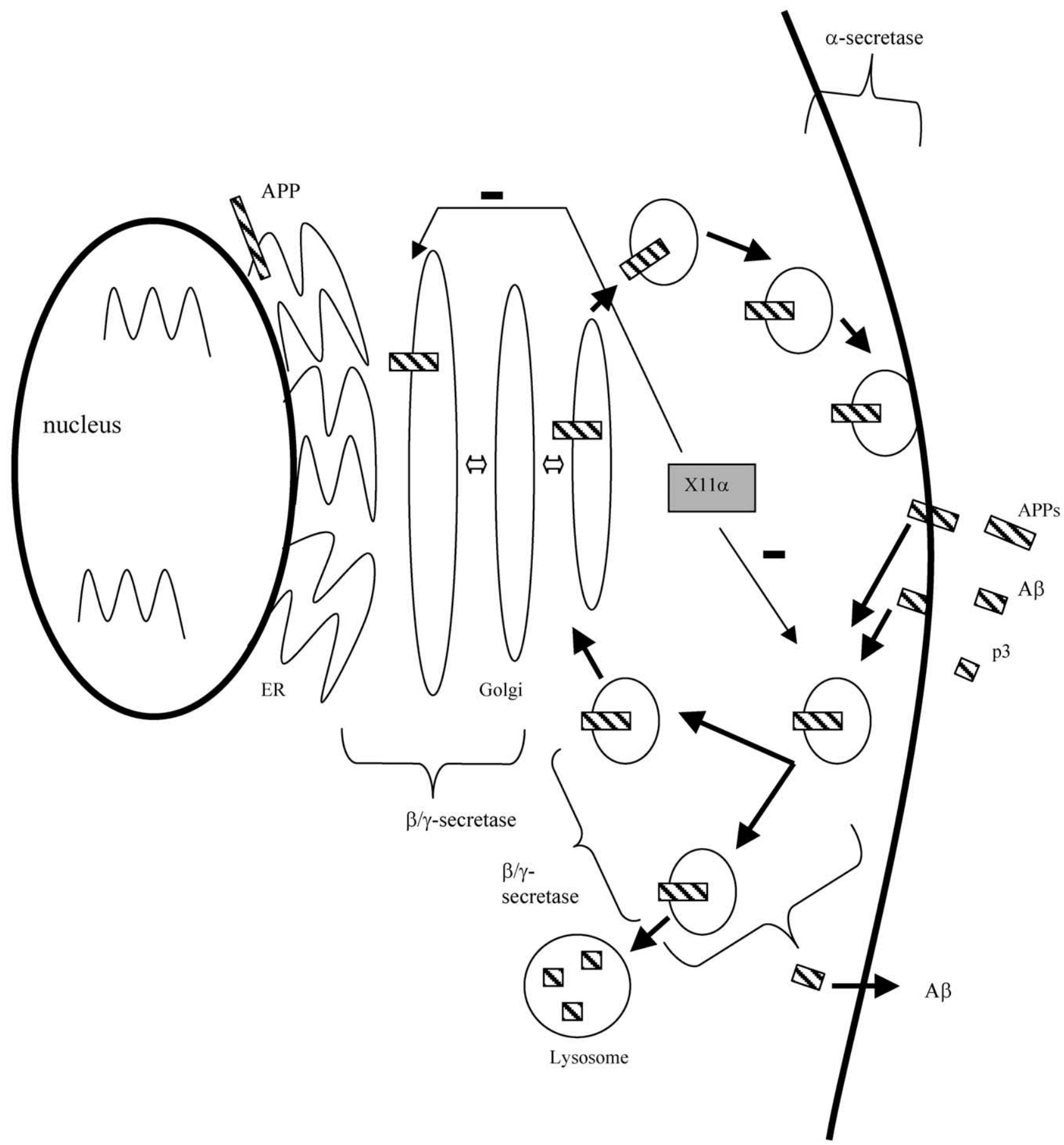

Fig. 7. X11 $\alpha$ modulates APP metabolism in secretory and endocytic pathways. APP is cotranslationally translocated into the ER, undergoes post-translational modifications (maturation) including glycosylation in the ER and Golgi, and transits to the cell surface. APP also undergoes endosomal/lysosomal catabolism after internalization from the cell surface, although some APP may be diverted directly from the secretory pathway. While $\alpha$-secretase cleavage occurs primarily at or near the cell surface in the secretory pathway, $\beta$ - and $\gamma$-secretase cleavage may occur in secretory and endocytic cellular compartments. As shown by delayed maturation, X11 $\alpha$ may retard egress of APP through the secretory pathway. X11 $\alpha$ may also impair endocytic trafficking and processing of APP, perhaps due to competitive interactions with the -YENP- motif. Thus, X11 $\alpha$ may inhibit APPswe metabolism in secretory and endocytic compartments and inhibit secretion of $A \beta 40$ and $A \beta 42$ generated by either pathway.

may be partially mimicked by APPswe in transfectable cell lines such as HEK 293 which possess much less $\beta$-secretase activity (Forman et al., 1998). However, proposed modulatory effects of X11 $\alpha$ on APP trafficking, metabolism, and function in neurons in brain in vivo remain speculative. 
Acknowledgements-This work was supported by grants from the American Federation for Aging Research, Alzheimer's Association, and US Public Health Service (P50 AG08671), and by the VAMC GRECC. Ms G. King is supported by an NINDS National Research Service Award. We thank Dr. N. Suzuki (Takeda) for antibodies BAN-50, BA-27, and BC-05, Drs. B. Margolis and J.-P. Borg (University of Michigan) for $X 11 \alpha$ constructs, and S. Skinner, Drs. C. Edwards, M. Gross (University of Michigan) for their assistance.

\section{REFERENCES}

Bayer TA, Cappai R, Masters CL, Beyreuther K, Multhaup G (1999) It all sticks together: the APP-related family of proteins and Alzheimer's disease. Mol Psychiatry 4:524-528.

Biederer T, Cao XW, Sudhof TC, Liu XR (2002) Regulation of APPdependent transcription complexes by Mint/X11s: differential functions of mint isoforms. J Neurosci 22:7340-7351.

Blanco G, Irving NG, Brown SDM, Miller CCJ, McLoughlin DM (1998) Mapping of the human and murine X11-like genes (APBA2 and Apba2), the murine Fe65 gene (Apbb1), and the human Fe65-like gene (APBB2): genes encoding phosphotyrosine-binding domain proteins that interact with the Alzheimer's disease amyloid precursor protein. Mammalian Genome 9:473-475.

Borg JP, Lopez-Figueroa MO, de Taddeo-Borg M, Kroon DE, Turner RS, Watson SJ, Margolis B (1999) Molecular analysis of the X11mLin-2/CASK complex in brain. J Neurosci 19:1307-1316.

Borg JP, Ooi J, Levy E, Margolis B (1996) The phosphotyrosine interaction domains of $\mathrm{X} 11$ and FE65 bind to distinct sites on the YENPTY motif of amyloid precursor protein. Mol Cell Biol 16:62296241.

Borg JP, Straight SW, Kaech SM, de Taddeo-Borg M, Kroon DE, Karnak D, Turner RS, Kim SK, Margolis B (1998a) Identification of an evolutionarily conserved heterotrimeric protein complex involved in protein targeting. J Biol Chem 273:31633-31636.

Borg JP, Yang YN, De Taddeo-Borg M, Margolis B, Turner RS (1998b) The $\mathrm{X} 11$ alpha protein slows cellular amyloid precursor protein processing and reduces $\mathrm{A}$ beta 40 and A beta 42 secretion. J Biol Chem 273:14761-14766.

Butz S, Okamoto M, Sudhof TC (1998) A tripartite protein complex with the potential to couple synaptic vesicle exocytosis to cell adhesion in brain. Cell 94:773-782.

Cao X, Sudhof TC (2001) A transcriptively active complex of APP with Fe65 and histone acetyltransferase Tip60. Science 293:115-120.

Cescato R, Dumermuth E, Spiess M, Paganetti PA (2000) Increased generation of alternatively cleaved beta-amyloid peptides in cells expressing mutants of the amyloid precursor protein defective in endocytosis. J Neurochem 74:1131-1139.

Chen YZ, McPhie DL, Hirschberg J, Neve RL (2000) The amyloid precursor protein-binding protein APP-BP1 drives the cell cycle through the S-M checkpoint and causes apoptosis in neurons. J Biol Chem 275:8929-8935.

Citron M, Oltersdorf T, Haass C, McConlogue L, Hung AY, Seubert P, Vigopelfrey C, Lieberburg I, Selkoe DJ (1992) Mutation of the beta-amyloid precursor protein in familial Alzheimers-disease increases beta-protein production. Nature 360:672-674.

Cupers P, Orlans I, Craessaerts K, Annaert W, De Strooper B (2001) The amyloid precursor protein (APP)-cytoplasmic fragment generated by gamma-secretase is rapidly degraded but distributes partially in a nuclear fraction of neurones in culture. $\mathrm{J}$ Neurochem 78:1168-1178.

Forman MS, Cook DG, Leight S, Doms RW, Lee VMY (1998) Differential effects of the Swedish mutant amyloid precursor protein on beta-amyloid accumulation and secretion in neurons and nonneuronal cells. J Neuropathol Exp Neurol 57:175.

Gao YH, Pimplikar SW (2001) Gamma-secretase cleaved C-terminal fragment of APP mediates signaling to the nucleus and represses retinoic acid-responsive transcription. Mol Biol Cell 12:1535.
Guenette SY, Chen J, Ferland A, Haass C, Capell A, Tanzi RE (1999) hFE65L influences amyloid precursor protein maturation and secretion. J Neurochem 73:985-993.

Gunawardena S, Goldstein LSB (2001) Disruption of axonal transport and neuronal viability by amyloid precursor protein mutations in Drosophila. Neuron 32:389-401.

Hase M, Yagi Y, Taru H, Tomita S, Sumioka A, Hori K, Miyamoto K, Sasamura T, Nakamura M, Matsuno K, Suzuki T (2002) Expression and characterization of the Drosophila X11-like/Mint protein during neural development. J Neurochem 81:1223-1232.

Ho A, Morishita W, Hammer RE, Malenka RC, Sudhof TC (2003) A role for Mints in transmitter release: Mint 1 knockout mice exhibit impaired GABAergic synaptic transmission. Proc Natl Acad Sci USA 100:1409-1414.

Homayouni R, Rice DS, Sheldon M, Curran T (1999) Disabled-1 binds to the cytoplasmic domain of amyloid precursor-like protein 1 . J Neurosci 19:7507-7515.

Howell BW, Lanier LM, Frank R, Gertler FB, Cooper JA (1999) The disabled 1 phosphotyrosine-binding domain binds to the internalization signals of transmembrane glycoproteins and to phospholipids. Mol Cell Biol 19:5179-5188.

Ide N, Hata Y, Hirao K, Irie M, Deguchi M, Yao I, Satoh A, Wada R, Takahashi K, Nakanishi H, Takai Y (1998) Interaction of rat lin-10 with brain-enriched F-actin-binding protein, neurabin-II/spinophilin. Biochem Biophys Res Communications 244:258-262.

Kamal A, Stokin GB, Yang ZH, Xia CH, Goldstein LSB (2000) Axonal transport of amyloid precursor protein is mediated by direct binding to the kinesin light chain subunit of kinesin-I. Neuron 28:449-459.

Kimberly WT, Zheng JB, Guenette SY, Selkoe DJ (2001) The intracellular domain of the beta-amyloid precursor protein is stabilized by Fe65 and translocates to the nucleus in a Notch-like manner. J Biol Chem 276:40288-40292.

Lai A, Gibson A, Hopkins CR, Trowbridge IS (1998) Signal-dependent trafficking of beta-amyloid precursor protein- transferrin receptor chimeras in Madin-Darby canine kidney cells. J Biol Chem 273: 3732-3739.

Lau KF, McLoughlin DM, Standen C, Miller CCJ (2000) X11 alpha and $\mathrm{x} 11$ beta interact with presenilin-1 via their PDZ domains. Mol Cell Neurosci 16:557-565.

Matsuda S, Yasukawa T, Homma Y, Ito Y, Niikura T, Hiraki T, Hirai S, Ohno S, Kita Y, Kawasumi M, Kouyama K, Yamamoto T, Kyriakis JM, Nishimoto I (2001) C-Jun N-terminal kinase (JNK)-interacting protein-1b/islet- brain-1 scaffolds Alzheimer's amyloid precursor protein with JNK. J Neurosci 21:6597-6607.

Maximov A, Sudhof TC, Bezprozvanny I (1999) Association of neuronal calcium channels with modular adaptor proteins. J Biol Chem 274:24453-24456.

McLoughlin DM, Irving NG, Miller CCJ (1998) The Fe65 and XII families of proteins: proteins that interact with the Alzheimer's disease amyloid precursor protein. Biochem Soc Trans 26:497-500.

McLoughlin DM, Standen CL, Lau KF, Ackerley S, Bartnikas TP, Gitlin JD, Miller CCJ (2001) The neuronal adaptor protein X11 alpha interacts with the copper chaperone for SOD1 and regulates SOD1 activity. J Biol Chem 276:9303-9307.

Mueller HT, Borg JP, Margolis B, Turner RS (2000) Modulation of amyloid precursor protein metabolism by $\mathrm{X} 11$ alpha/Mint-1: a deletion analysis of protein-protein interaction domains. J Biol Chem 275:39302-39306.

Okamoto M, Sudhof TC (1997) Mints, Munc18-interacting proteins in synaptic vesicle exocytosis. J BiolChem 272:31459-31464

Okamoto M, Sudhof TC (1998) Mint 3: a ubiquitous mint isoform that does not bind to munc18-1 or -2. Eur J Cell Biol 77:161-165.

Okamoto T, Takeda S, Giambarella U, Murayama Y, Matsui T, Katada T, Matsuura Y, Nishimoto I (1996) Intrinsic signaling function of APP as a novel target of three V642 mutations linked to familia Alzheimer's disease. EMBO J 15:3769-3777.

Okamoto T, Takeda S, Murayama Y, Ogata E, Nishimoto I (1995) 
Ligand-dependent G-protein coupling function of amyloid transmembrane precursor. J Biol Chem 270:4205-4208.

Oltersdorf T, Ward PJ, Henriksson T, Beattie EC, Neve R, Lieberburg I, Fritz LC (1990) The Alzheimer amyloid precursor protein: identification of a stable intermediate in the biosynthetic degradative pathway. J Biol Chem 265:4492-4497.

Perez RG, Soriano S, Hayes JD, Ostaszewski B, Xia WM, Selkoe DJ, Chen XH, Stokin GB, Koo EH (1999) Mutagenesis identifies new signals for beta-amyloid precursor protein endocytosis, turnover, and the generation of secreted fragments, including A beta 42 . J Biol Chem 274:18851-18856.

Perez RG, Squazzo SL, Koo EH (1996) Enhanced release of amyloid beta-protein from codon 670/671 "Swedish" mutant beta-amyloid precursor protein occurs in both secretory and endocytic pathways. J Biol Chem 271:9100-9107.

Rongo C, Whitfield CW, Rodal A, Kim SK, Kaplan JM (1998) LIN-10 is a shared component of the polarized protein localization pathways in neurons and epithelia. Cell 94:751-759.

Russo C, Dolcini V, Salis S, Venezia V, Zambrano N, Russo T, Schettini G (2002) Signal transduction through tyrosine-phosphorylated C-terminal fragments of amyloid precursor protein via an enhanced interaction with Shc/Grb2 adaptor proteins in reactive astrocytes of Alzheimer's disease brain. J Biol Chem 277:3528235288.

Sabo SL, Ikin AF, Buxbaum JD, Greengard P (2001) The Alzheimer amyloid precursor protein (APP) and FE65, an APP-binding protein, regulate cell movement. J Cell Biol 153:1403-1414.

Sabo SL, Lanier LM, Ikin AF, Khorkova O, Sahasrabudhe S, Greengard P, Buxbaum JD (1999) Regulation of beta-amyloid secretion by FE65, an amyloid protein precursor-binding protein. J Biol Chem 274:7952-7957.

Sastre M, Turner RS, Levy E (1998) X11 interaction with beta-amyloid precursor protein modulates its cellular stabilization and reduces amyloid beta-protein secretion. J Biol Chem 273:22351-22357.

Scheinfeld MH, Roncarati R, Vito P, Lopez PA, Abdallah M, D'Adamio L (2002) Jun NH2-terminal kinase (JNK) interacting protein 1 (JIP1) binds the cytoplasmic domain of the Alzheimer's beta-amyloid precursor protein (APP). J Biol Chem 277:3767-3775.

Selkoe DJ (2001) Presenilins, beta-amyloid precursor protein and the molecular basis of Alzheimer's disease. Clin Neurosci Res 1:91103.

Setou M, Nakagawa T, Seog DH, Hirokawa N (2000) Kinesin superfamily motor protein KIF17 and mLin-10 in NMDA receptor-containing vesicle transport. Science 288:1796-1802.

Steinhilb ML, Turner RS, Gaut JR (2001) The protease inhibitor, MG132, blocks maturation of the amyloid precursor protein Swedish mutant preventing cleavage by beta-secretase. J Biol Chem 276:4476-4484.

Suzuki N, Cheung TT, Cai XD, Odaka A, Otvos L, Eckman C, Golde TE, Younkin SG (1994) An increased percentage of long amyloidbeta protein secreted by familial amyloid-beta protein-precursor (beta-App(717)) mutants. Science 264:1336-1340.
Tanahashi H, Tabira T (1999a) Genomic organization of the human $\mathrm{X} 11 \mathrm{~L} 2$ gene (APBA3), a third member of the $\mathrm{X} 11$ protein family interacting with Alzheimer's beta-amyloid precursor protein. Neuroreport 10:2575-2578.

Tanahashi H, Tabira T (1999b) X11L2, a new member of the X11 protein family, interacts with Alzheimer's beta-amyloid precursor protein. Biochem Biophys Res Comm 255:663-667.

Tarr PE, Roncarati R, Pelicci G, Pelicci PG, D'Adamio L (2002) Tyrosine phosphorylation of the beta-amyloid precursor protein cytoplasmic tail promotes interaction with Shc. J Biol Chem 277:1679816804.

Tomita S, Kirino Y, Suzuki T (1998) A basic amino acid in the cytoplasmic domain of Alzheimer's beta-amyloid precursor protein (APP) is essential for cleavage of APP at the alpha-site. J Biol Chem 273:19304-19310.

Trommsdorff R, Borg JP, Margolis B, Herz J (1998) Interaction of cytosolic adaptor proteins with neuronal apolipoprotein $\mathrm{E}$ receptors and the amyloid precursor protein. J Biol Chem 273:33556-33560.

Turner RS, Suzuki N, Chyung ASC, Younkin SG, Lee VMY (1996) Amyloids beta(40) and beta(42) are generated intracellularly in cultured human neurons and their secretion increases with maturation. J Biol Chem 271:8966-8970.

Walhout AJM, Sordella R, Lu XW, Hartley JL, Temple GF, Brasch MA, Thierry-Mieg N, Vidal M (2000) Protein interaction mapping in Celegans using proteins involved in vulval development. Science 287:116-122.

Weidemann A, Konig G, Bunke D, Fischer P, Salbaum JM, Masters $\mathrm{CL}$, Beyreuther K (1989) Identification, biogenesis, and localization of precursors of Alzheimers-disease A4 amyloid protein. Cell 57: 115-126.

Yu G, Chen FS, Nishimura M, Steiner H, Tandon A, Kawarai T, Arawaka S, Supala A, Song YQ, Rogaeva E, Holmes E, Zhang DM, Milman P, Fraser PE, Haass C, St George-Hyslop P (2000) Mutation of conserved aspartates affects maturation of both aspartate mutant and endogenous presenilin 1 and presenilin 2 complexes. J Biol Chem 275:27348-27353

Zambrano N, Bruni P, Minopoli G, Mosca R, Molino D, Russo C, Schettini G, Sudol M, Russo T (2001) The beta-amyloid precursor protein APP is tyrosine-phosphorylated in cells expressing a constitutively active form of the Abl protoncogene. J Biol Chem 276: 19787-19792.

Zambrano N, Minopoli G, de Candia P, Russo T (1998) The Fe65 adaptor protein interacts through its PID1 domain with the transcription factor CP2/LSF/LBP1. J Biol Chem 273:20128-20133.

Zhang ZT, Lee CH, Mandiyan V, Borg JP, Margolis B, Schlessinger J, Kuriyan J (1997) Sequence-specific recognition of the internalization motif of the Alzheimer's amyloid precursor protein by the X11 PTB domain. EMBO J 16:6141-6150.

Zheng PZ, Eastman J, Vande Pol S, Pimplikar SW (1998) PAT1, a microtubule-interacting protein, recognizes the basolateral sorting signal of amyloid precursor protein. Proc Natl Acad Sci USA 95:14745-14750. 